Check for updates

Cite this: RSC Adv., 2018, 8, 20334

\title{
Silver nanoparticle modified surfaces induce differentiation of mouse kidney-derived stem cells $\uparrow$
}

\author{
Neelika Roy Chowdhury, ${ }^{a}$ Isabel Hopp, ${ }^{b}$ Peter Zilm, ${ }^{c}$ Patricia Murray*b \\ and Krasimir Vasilev (iD *a
}

In this paper, we interrogate the influence of silver nanoparticle (AgNPs)-based model surfaces on mouse kidney-derived stem cells (mKSCs) differentiation. The widespread use of silver in biomedical and consumer products requires understanding of this element's effect on kidney cells. Moreover, the potential for using stem cells in drug discovery require methods to direct their differentiation to specialized cells. Hence, we generated coated model substrates containing different concentrations of surface immobilized AgNPs, and used them to evaluate properties and functions of mKSCs. Initially, mKSCs exhibited reduced viability on higher silver containing surfaces. However, longer culture periods assisted mKSCs to recover. Greater degree of cell spreading and arborization led by AgNPs, suggest podocyte differentiation. Proximal tubule cell marker's expression revealed differentiation to the specific lineage. Although the exact mechanism underpinning these findings require significant future efforts, this study demonstrate silver's capacity to stimulate mKSC differentiation, which may provide opportunities for drug screenings.

Received 11th March 2018

Accepted 29th May 2018

DOI: $10.1039 / \mathrm{c} 8 \mathrm{ra} 02145 \mathrm{~g}$

rsc.li/rsc-advances

Chronic kidney disease (CKD) is recognized as a serious

\section{Introduction}

Silver and silver nanoparticles (AgNPs) have been utilized in a number of consumer products because of their capacity to kill bacteria. ${ }^{1-7}$ In medicine, silver coated catheters, wound dressings and a range of other devices are currently used on a daily basis. ${ }^{3,8}$ With the potential benefits brought by the antibacterial properties of silver come concerns regarding toxicity to mammalian cells, tissues and overall human health. Although mammalian cells can generally tolerate greater amounts of silver than bacteria, the element can also be toxic to tissues if used in high concentrations. ${ }^{9-11}$ The inflammatory response to silver is still an open question with the area being rather controversial. Many studies claim reduced inflammation or no alteration of inflammatory response while others report adverse responses. Another area that needs further attention is related to the effect of silver on stem cell fate. We have recently looked at the effect of silver on the differentiation of mesenchymal stem/stromal cell (MSC) and found that oxidative stress caused by the silver led to preferential differentiation to adipocytes rather than osteoblasts. ${ }^{12}$ This report demonstrated the need for greater attention to how silver may affect stem cells.

${ }^{a}$ School of Engineering, University of South Australia, Mawson Lakes, SA 5095, Australia. E-mail: Krasimir.vasilev@unisa.edu.au

${ }^{b}$ Institute of Translational Medicine, University of Liverpool, Liverpool, UK. E-mail: P. A.Murray@liverpool.ac.uk

'Microbiology Laboratory, Adelaide Dental School, The University of Adelaide, Adelaide, SA 5005, Australia

$\dagger$ Electronic supplementary information (ESI) available. See DOI: $10.1039 / \mathrm{c} 8 \mathrm{ra02145g}$ global health problem. ${ }^{13}$ End stage renal disease (ESRD) is the final stage of $\mathrm{CKD}$ and is associated with high rates of morbidity and mortality, as well being financially costly, with the United States alone spending >US\$ 50,000 for each patient suffering from ESRD. Although current therapeutic interventions slow down the progression of CKD to ESRD, the current state of treatment does not generate satisfactory outcomes in all patients. ${ }^{14}$ Therefore, it is extremely important to develop new treatment strategies where stem cells can be directed to differentiate to specialized renal cell types that could be useful to treat CKD in order to prevent ESRD progression.

The kidney is a highly complex organ with several distinct cell types ${ }^{15}$ but two cell types in particular, podocytes and proximal tubule cells (PTCs), play crucial roles in maintaining normal kidney function. For instance, podocytes are required to maintain the glomerular filtration barrier, and PTCs are necessary for secreting metabolites into the tubular lumen, and for the absorption of various molecules from the glomerular filtrate. PTCs also play a role in drug metabolism, and consequently, drug-induced nephrotoxicity is a major cause of kidney disease. ${ }^{16-18}$ Podocytes and PTCs are difficult cells to culture because the former are post-mitotic and the latter rapidly lose their phenotype following isolation from the kidney. There has thus been great interest in generating these cell types from stem cells in order to understand their physiology, investigate how this becomes altered in kidney disease, and to use them in drug screening programs.

We have previously isolated stem cells from neonatal mouse kidneys that are able to generate podocytes and proximal tubule 
cells (PTCs) in vitro, and ex vivo when transplanted into mouse embryo kidneys. ${ }^{\mathbf{1 9 2 0}}$ Recent reports have also demonstrated that the chemistry and nanotopography of cell culture surfaces regulate the proliferation and differentiation of various stem cell lines. ${ }^{\mathbf{1 4 2 1 , 2 2}}$ MacGregor-Ramiasa et al. have investigated the effect of concentration gradient of $-\mathrm{NH}_{2}$ functional groups on the differentiation of a clonal kidney stem cell (mKSCs) line derived from neonatal mouse kidney. Differentiation of proximal-tubule-like cells was observed on the surfaces with low amine content by the expression of specific markers. ${ }^{23}$

With the increased promise of cell therapies and the wide application of silver containing products in medicine and everyday life, it becomes important to evaluate the effect of silver based antibacterial coatings on mKSC fate. In this work, we used established platforms for generation of antibacterial surfaces combining plasma polymer coatings and silver nanoparticles. ${ }^{6}$ These types of surfaces were selected since they were demonstrated in our previous work to have excellent antibacterial properties but no toxicity to primary human fibroblasts or MSCs. The method of preparation also allowed us to generate two different silver nanoparticle surface concentrations which facilitated examination of dose dependent effects. ${ }^{\mathbf{6}, 12}$ The effect of the silver nanoparticle modified surface on the attachment, proliferation, viability, spreading and differentiation of mKSCs was evaluated via microscopic and immunostaining techniques.

\section{Experimental}

\section{Materials}

2-Methyl-2-oxazoline, $\mathrm{NaOH}$ pellets, phosphate buffer saline (PBS) tablets, foetal bovine serum (FBS), 2-mercaptosuccinic acid (MSA) (97\%), sodium borohydride $\left(\mathrm{NaBH}_{4}\right)$, nitric acid (70\%) were purchased from Sigma-Aldrich Australia and used as received. Hydrochloric acid (36\%, Ajax Finechem Pty. Ltd. Australia) was used as received. Dulbecco's Modified Eagle Medium (DMEM) was purchased from Gibco. Penicillin, streptomycin, L-glutamine, MEM non-essential amino acids, cell counting kit-8 (CCK-8), Naphthol AS-MX phosphate and Fast Red TR were obtained from Sigma. Silver nitrate $\left(\mathrm{AgNO}_{3}\right)$ and glass coverslips were bought from ProSciTech, Australia. Ultrapure MilliQ water (resistivity 18.2 $\Omega$ ) was used for all experiments and cleaning procedures.

\section{Plasma deposition of 2-methyl-2-oxazoline}

A custom built capacitively coupled bell-chamber reactor with a $13.56 \mathrm{MHz}$ plasma generator and a matching network (Advanced Energy, USA) described elsewhere ${ }^{24}$ was used for plasma deposition. $13 \mathrm{~mm}$ glass coverslips and silicon wafers were cleaned with ethanol, dried with nitrogen stream and stored in airtight containers until further use. The substrates were cleaned using air plasma (50 W, 5 minutes, $\left.2 \times 10^{-1} \mathrm{mbar}\right)$ prior to any plasma treatment. Deposition of 2-methyl-2oxazoline was carried out at $50 \mathrm{~W}$ for 2 minutes at a precursor pressure of $2 \times 10^{-1} \mathrm{mbar}$. To stabilize the plasma coating, the substrates were kept overnight at room temperature in sealed containers prior to any further modification.

\section{Synthesis of AgNPs@MSA}

Silver nanoparticles were synthesized by sodium borohydride reduction of silver nitrate. ${ }^{6}$ Briefly, $12 \mathrm{ml}$ of $2 \mathrm{mM} \mathrm{AgNO}_{3}$ was mixed with $5 \mathrm{ml}$ of $2 \mathrm{mM}$ MSA under ice cold condition. $0.5 \mathrm{ml}$ of $0.5 \mathrm{M}$ of $\mathrm{NaBH}_{4}$ was added to the solution under vigorous stirring. The color of the solution mixture turned to reddish brown after the addition of $\mathrm{NaBH}_{4}$ indicated the formation of AgNPs. The AgNPs were stored in light proof container until further use. The solutions remain stable for several months without showing any visible aggregation of particles.

\section{Immobilization of AgNPs@MSA on pPOX substrates}

The plasma modified substrates were incubated at room temperature in AgNPs solution for time intervals of 6 and $24 \mathrm{~h}$. Depending on the AgNPs@MSA immobilization time the samples will be represented as $\mathrm{S}_{\mathrm{L}}$ and $\mathrm{S}_{\mathrm{H}}(6$ and $24 \mathrm{~h}$ AgNPs@MSA immobilization time respectively) in this paper. After incubation the AgNPs@MSA solution was discarded and the samples were rinsed 3 times with MilliQ water to remove any loosely bound AgNPs. Then the samples were dried with nitrogen stream and stored in airtight container until further use.

Glass coverslips were used for atomic force microscope (AFM) and cell culture studies, while silicon wafers were used for ellipsometry and X-ray photoelectron spectroscopy (XPS).

\section{Surface characterization}

Ellipsometry. A Variable Angle Spectroscopic Ellipsometer (VASE) (J. A. Woollam Co. Inc.) equipped with a HS-190 high speed monochromator and a VB-400 control module, was used to determine the thickness of plasma polymer films. All measurements were carried out at different angles from $65^{\circ}$ to $75^{\circ}$ at an interval of $5^{\circ}$ and, over a wavelength range of 250 to $1100 \mathrm{~nm}$ with $10 \mathrm{~nm}$ increment. WVASE32 software was used for running the setup, calibration, data collection and analysis. Inbuilt Cauchy algorithm was used to fit the data. For each plasma deposition condition, thickness measurements were conducted on three technical replicates of the coating.

Atomic force microscopy (AFM). The topographical analysis of the prepared samples was carried out by an NT-MDT NTEGRA SPM (Moscow, Russia) AFM in non-contact mode. Silicon nitride non-contact cantilevers with gold coating on the reflective side (NT-MDT, NSG03) and resonance frequencies between 50 and $150 \mathrm{kHz}$ were used. The tips spring constant is between 0.35 and $6.06 \mathrm{~N} \mathrm{~m}^{-1}$, as measured by the Sader method. ${ }^{25}$ The amplitude of oscillation was $10 \mathrm{~nm}$, and the scan rate for $5 \mu \mathrm{m}$ $\times 5 \mu \mathrm{m}$ images was $1.0 \mathrm{~Hz}$. The scanner used had a maximum range of $100 \mu \mathrm{m}$ and was calibrated in $x, y$ and $z$ directions using $1.5 \mu \mathrm{m}$ standard grids with a height of $22 \mathrm{~nm}$.

Scanning electron microscopy (SEM). A scanning electron microscope (Carl Zeiss Microscopy Merlin with GEMINI II column) was used to investigate the silicon wafers substrates after the immobilization of AgNPs@MSA. The microscope was 
operated at $2 \mathrm{kV}$ with high-resolution column mode (probe current: $100 \mathrm{pA}$ ). The secondary electron images were recorded by on-axis in-lens secondary electron detector.

X-ray photo electron spectroscopy (XPS). XPS was used to analyze the chemical composition of the surfaces before and after the plasma polymerization and AgNPs@MSA immobilization. All surfaces were characterized using a Spec SAGE XPS equipped with a monochromatic $\mathrm{Mg}$ radiation source operating at $10 \mathrm{kV}$ and $20 \mathrm{~mA}$. For the quantification of the atomic concentrations of all samples, survey spectra were recorded over the binding energy range of $0-1000 \mathrm{eV}$ at a pass energy of $100 \mathrm{eV}$ and with $0.5 \mathrm{eV}$ resolution. All the binding energies were referenced to the $\mathrm{C} 1 \mathrm{~s}$ neutral carbon peak at $285 \mathrm{eV}$, to compensate for the effect of surface charging. Casa XPS software was used for the processing and curve fitting of all resulting spectra.

\section{Cell culture}

All solutions and buffers used during cell culture were prewarmed to $37^{\circ} \mathrm{C}$ prior to use. The stem cell line was derived from neonatal mouse kidney by Fuente Mora et al. ${ }^{19}$ Cells were cultured in DMEM in standard tissue culture plates (TCPs). The medium was changed every 2-3 days and cells were incubated with $5 \% \mathrm{CO}_{2}$ at $37{ }^{\circ} \mathrm{C} .13 \mathrm{~mm}$ coated and uncoated glass coverslips were placed in 24 well TCPs and mKSCs were seeded at a density of 10000 cells per well and incubated for a period of 48 and $96 \mathrm{~h}$. Care was taken to ensure that the cell suspension was evenly distributed during plating.

Cell viability. To determine cell viability, after each incubation period, DMEM was aspirated and cells were washed 3 times with PBS. $150 \mu \mathrm{L}$ of $10 \%$ CCK-8 (diluted in DMEM $1: 10$ ) was added to each well and cells were incubated for $1 \mathrm{~h}$. Then $100 \mu \mathrm{L}$ of the reaction solution was transferred into a 96 well plate. The absorbance of the solution was measured by an Anthos Labtec LP400 spectrophotometer at wavelength of $450 \mathrm{~nm}$ for detection (620 $\mathrm{nm}$ reference filter). The background of the culture medium was measured and subtracted from all values.

Cell proliferation, population doubling time (PDT) and extent of cell spreading. Cells were fixed using $4 \%(\mathrm{w} / \mathrm{v})$ paraformaldehyde (PFA) for 15 minutes and then incubated in phalloidin (diluted in PBS $5: 200$ ) labelled with Alexa Fluor ${ }^{\circledR}$ 488 (Invitrogen) for 30 minutes at room temperature in the dark and then nuclei were stained with 4',6-diamidino-2phenylindole (DAPI). Samples were imaged under epifluorescence illumination using a Leica DM2500 microscope fitted with a Leica DFC420C camera. An average of 10 images per coverslip was taken and cell number quantified by counting stained nuclei from the images obtained. All images are representative for the entire surface from the corresponding sample. The extent of cell spreading (phalloidin-stained cells) was measured using ImageJ.

From the total cell numbers at different time points, the mKSC population doubling times (PDTs) were calculated with the help of non-linear regression analysis using the following equation:

$$
\mathrm{PDT}=\ln (2) / K
$$

where $K$ is the rate constant.

Cytology - methylene blue (MB) staining. For morphological evaluation, cells were fixed with 4\% PFA for 15 minutes, washed with PBS and stained with a solution of $200 \mu \mathrm{L} 0.5 \%(\mathrm{v} / \mathrm{v})$ methylene blue in $\mathrm{dH}_{2} \mathrm{O}$ for 10 minutes at room temperature and washed with PBS. Samples were analyzed using a light microscope.

Podocyte quantification. Phalloidin-labelled cells were imaged after $96 \mathrm{~h}$ and podocyte-like cells were identified based on their morphology including arborized appearance, high cytoplasmic-to-nuclear ratio and binucleation. Podocytes were quantified microscopically following established proce${\text { dures. }{ }^{19,20,23,26}}_{10}$ images per coverslip were acquired and analyzed. Quantification of podocyte-like cells was carried out relative to the cells that did not show typical podocyte morphology. All images are representative for the entire surface from one sample.

Immunofluorescence. For immunofluorescence, cells were fixed at room temperature with $4 \%(\mathrm{w} / \mathrm{v})$ PFA for 5 minutes, washed $3 \times$ with PBS and then incubated for $1 \mathrm{~h}$ at room temperature in blocking solution $(10 \%(\mathrm{v} / \mathrm{v})$ normal goat serum). The serum was removed after the first incubation and a second incubation was carried out overnight at $4{ }^{\circ} \mathrm{C}$ with primary antibody solutions that contained $1 \%(\mathrm{v} / \mathrm{v})$ goat serum, $0.1 \%(\mathrm{w} / \mathrm{v})$ Triton-X 100 in PBS and the primary antibodies (Table 1) at the required concentrations. The following day, cells were washed $3 \times$ with PBS, and incubated for $2 \mathrm{~h}$ at room temperature with the required concentration of secondary antibody (Table 1 ) in $1 \%(\mathrm{v} / \mathrm{v})$ goat serum and $0.1 \%(\mathrm{w} / \mathrm{v})$ Triton$\mathrm{X} 100$ in PBS. Cells were then washed $3 \times$ with PBS and counterstained with DAPI.

For quantification of images, an average of 10 images were taken from each sample and number of positive cells was quantified. Images shown represent the entire sample surface as well as an average of all experiments.

Alkaline phosphatase activity assay. On day 4 after seeding, cells were washed three times with PBS and fixed in $4 \%(\mathrm{w} / \mathrm{v})$ PFA for 5 minutes. Then the cells were equilibrated in Tris$\mathrm{HCl}(\mathrm{pH}$ 9.2) for 5 minutes at room temperature, followed by an

Table 1 Primary and secondary antibodies

\begin{tabular}{lllll}
\hline & Name & Type & Concentration & Manufacturer \\
\hline Primary antibody & LRP2 megalin & Mouse monoclonal IgG1 & $1: 200$ & Acris, DM3613P \\
& Podocalyxin & Mouse monoclonal IgG2 & $1: 200$ & R \& D systems, MAB1556 \\
Secondary antibody & Alexa Fluor 594 goat $\alpha$ mouse & IgG1-594 & $1: 1000$ & Invitrogen, A-21125
\end{tabular}


incubation in a solution containing $2 \mathrm{mg} 0.02 \%$ (w/v) Naphthol AS-MX phosphate and $10 \mathrm{mg}$ 0.1\% (w/v) Fast Red TR in $10 \mathrm{ml}$ Tris- $\mathrm{HCl}$ (pH 9.2) for 15 minutes at room temperature in the dark. The reaction solution was then removed and cells were washed once with Tris- $\mathrm{HCl}$ pH 9.2 and twice with PBS. Cells were co-stained with DAPI.

All experiments were performed with three biological and technical replicates. Methyl-oxazoline plasma polymerized surfaces and uncoated glass coverslips were used as positive (PC) and negative controls (NC) respectively for all cell culture experiments.

\section{Results and discussion}

\section{Substrate preparation and characterization}

To generate model substrates which facilitate understanding of the effect of silver-based coating on the fate of mKSCs, we used silver nanoparticles (AgNPs@MSA) that we reported earlier. ${ }^{6}$

We knew that coatings generated using these nanoparticles have excellent antibacterial properties and are non-cytotoxic to primary human fibroblasts and mesenchymal stem cells. ${ }^{\mathbf{6}, 12}$ Our early approach to immobilize these nanoparticles to the surface was via electrostatic coupling to allylamine plasma polymer films which are known to retain significant number of amine groups. ${ }^{27,28}$ In this work, we used covalent attachment of the nanoparticle to the substrate since it presents a more stable platform compared to electrostatic binding. ${ }^{29}$ To achieve this, we used relatively recent plasma polymer coatings developed by our group which are prepared from oxazoline (pPOX) based precursors. The resultant films have been demonstrated to retain a population of intact oxazoline functionalities which can be used to covalently bind nanoparticles and ligands containing carboxylic acid groups. ${ }^{30-32}$ The conditions selected for the plasma deposition resulted in a film thickness of $25.01 \pm$ $0.03 \mathrm{~nm}$ as measured by ellipsometry. AgNPs@MSA were immobilized by immersion of the plasma polymer modified surface in a solution of silver nanoparticles for predetermined time (Fig. 1A).

After AgNPs@MSA immobilization, the samples showed a homogenous light brownish colour which is due to the plasmon resonance adsorption of the silver nanoparticles (Fig. 1B, II). The AgNPs@MSA were spherical with an average size of 12.27 nm similar to those in ref. 6. The SEM analysis showed uniform particle distribution on the plasma modified surfaces and absence of aggregations (Fig. 1C). AFM imaging before the immobilization of the AgNPs@MSA (Fig. SI 1A $\dagger$ ) demonstrated that the coatings are continuous, pin hole free with a surface roughness of $0.569 \mathrm{~nm}$ (Fig. SI $1 \mathrm{C}^{\dagger}$ ). The surface roughness increased to $5.511 \mathrm{~nm}$ after the deposition of AgNPs@MSA (Fig. SI 1D $\dagger$ ). XPS survey spectra of the unmodified glass coverslips (NC), pPOX coated substrates (PC) and pPOX surfaces with the immobilized AgNPs@MSA is shown in Fig. 1D. As expected, only three elements are present on the bare glass surface - carbon, oxygen and silicone. Substrates with pPOX plasma polymer film showed the presence of nitrogen, in addition to carbon and oxygen, which is consistent with the chemical composition of the precursor. Along with the carbon,

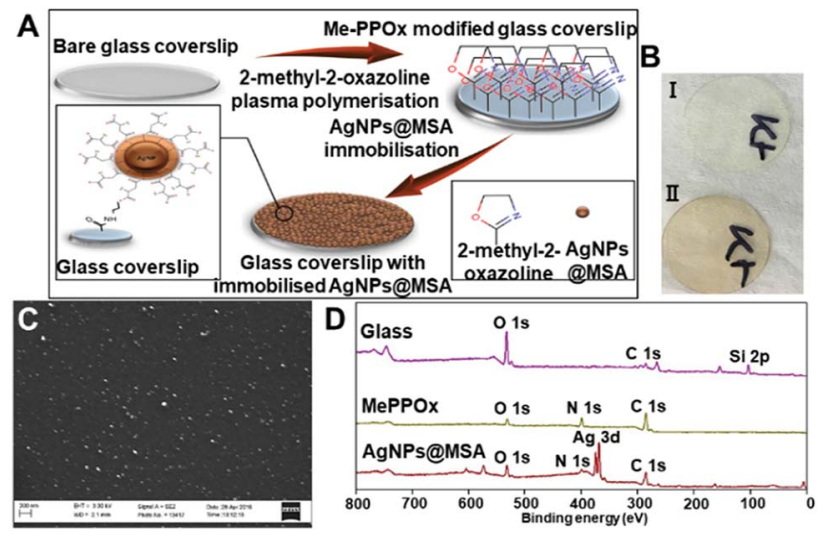

Fig. 1 (A) Schematic of fabrication process of plasma and AgNPs@MSA modified glass substrates, (B) GCS before (I) and after AgNPs@MSA immobilization for $24 \mathrm{~h}$ (II), (C) SEM image of AgNPs@MSA immobilized for $24 \mathrm{~h}$, (D) XPS survey spectra of glass coverslips without modification (NC), after applying methyl oxazoline plasma polymer coating (PC), and after immobilization of AgNPs@MSA for $24 \mathrm{~h}$.

Table 2 Atomic concentration of chemical elements determined by XPS on the surface of glass coverslips without modification (NC), after applying a methyl oxazoline plasma polymer coating (PC), and after immobilization of AgNPs@MSA for $6 \mathrm{~h}\left(\mathrm{~S}_{\mathrm{L}}\right)$ and $24 \mathrm{~h}\left(\mathrm{~S}_{\mathrm{H}}\right)$

\begin{tabular}{llrrrl}
\hline & C1s & N1s & \multicolumn{1}{c}{ O1s } & Si2p & Ag3d \\
\hline NC & 15.62 & & 54.00 & 30.36 & \\
PC & 72.45 & 18.06 & 9.48 & & \\
$\mathrm{~S}_{\mathrm{L}}$ & 48.58 & 30.90 & 11.98 & & 8.61 \\
$\mathrm{~S}_{\mathrm{H}}$ & 46.74 & 22.20 & 17.10 & & 13.95 \\
\hline
\end{tabular}

nitrogen and oxygen a distinct Ag3d peak was detected when AgNPs@MSA were immobilized on the plasma polymer modified samples. The atomic concentration of chemical elements on the surface of the samples is presented in Table 2. $\mathrm{S}_{\mathrm{H}}$ and $\mathrm{S}_{\mathrm{L}}$ denote different time of nanoparticle immobilization for $24 \mathrm{~h}$ and $6 \mathrm{~h}$, respectively. As anticipated the atomic concentration of silver increased with the time of immobilization from $8.61 \pm$ $0.3 \%\left(6 \mathrm{~h}\right.$, samples $\left.\mathrm{S}_{\mathrm{L}}\right)$ to $13.95 \pm 0.1 \%\left(24 \mathrm{~h}\right.$, samples $\left.\mathrm{S}_{\mathrm{H}}\right)$. Longer immobilization time resulted in greater silver concentration corresponding to greater number of nanoparticles binding to the surface. This time dependent immobilization process allowed us to generate surfaces with different and controlled concentration of silver nanoparticles. Both silver surface concentrations are sufficient to completely eliminate bacterial growth as we demonstrated in ref. 6, however, this allows us to test the influence of different silver surface concentration on the fate of mKSCs.

\section{Effect of silver nanoparticle concentration on mKSC viability, proliferation and morphology}

The viability of mKSCs cultured on silver nanoparticle modified surfaces and controls was determined using the CCK-8 kit assay (Fig. 2A). The results indicate strong reduction in cell viability 


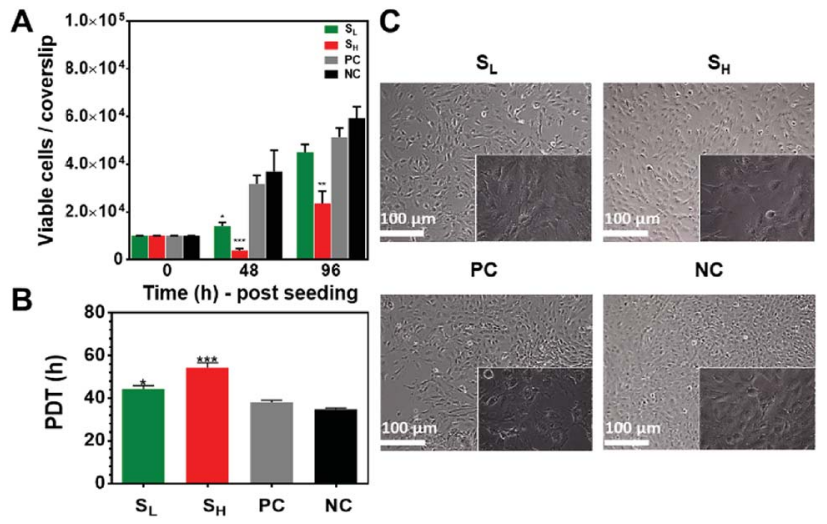

Fig. 2 Viability, population doubling time (PDT) and morphology of mKSCs cultured on flat (NC) and nanorough (PC, $S_{L}$ and $S_{H}$ ) test substrates. (A) Number of viable cells as determined by CCK- 8 assay, (B) population doubling time. $\mathrm{S}_{\mathrm{H}}$ and $\mathrm{S}_{\mathrm{L}}$ denotes surfaces having AgNPs@MSA deposited for 6 and 24 h, respectively, PC-methyl oxazoline plasma polymer coated samples and NC-unmodified glass coverslips. Scale bars for all images $100 \mu \mathrm{m}$. (C) Phase contrast images of mKSCs on the glass coverslips after AgNPs@MSA immobilization for $6 \mathrm{~h}\left(\mathrm{~S}_{\mathrm{L}}\right)$ and $24 \mathrm{~h}\left(\mathrm{~S}_{\mathrm{H}}\right)$ at $48 \mathrm{~h}$, after methyl oxazoline plasma deposition (PC) and unmodified glass coverslips (NC) (10x; magnified inserts $40 \times)$. Data are presented as the mean $\pm \operatorname{SEM}(n=9) ; * p<0.05 ; * * p<$ $0.01 ; * * * p<0.001$. Asterisks indicate statistical significance compared to the uncoated glass coverslips (NC).

after $48 \mathrm{~h}$ in culture, particularly for the higher silver nanoparticle concentration. However, the cells recovered after $96 \mathrm{~h}$, especially at the lower nanoparticle concentration where cell viability was only $15-20 \%$ lower compared to than on control substrates without silver. The reduced initial viability and attachment of the cell on the silver containing samples could be due to the substantial amount of released silver ions from the surfaces. ${ }^{6,12}$ The silver ions are the active species that make silver such a potent antibacterial agent but the element could be toxic to mammalian cells too. In a pioneering study we demonstrated the mammalian cells can tolerate greater amount of silver than bacteria. Our finding was also confirmed by others and our follow up studies ${ }^{3,6,12}$ which showed that amounts of silver lethal to bacteria did not significantly affect primary human fibroblasts and mesenchymal stem cells (MSCs). However, mammalian cells may have different tolerance to silver and our current study demonstrate that, although capable of recovery, the viability of mKSCs was reduced in the early stages of growth. Overall, these data suggest both time- and concentration-dependent effects of silver nanoparticles on mKSC viability.

We also assessed the mKSC population doubling time (Fig. 2B). It was greater on the silver nanoparticle modified surface i.e. $45 \mathrm{~h}$ and $>52 \mathrm{~h}$ for $\mathrm{S}_{\mathrm{L}}$ and $\mathrm{S}_{\mathrm{H}}$, respectively. In comparison, the PDT was $<40 \mathrm{~h}$ on control surfaces.

\section{Podocyte differentiation}

mKSCs have been shown to differentiate on surfaces to podocytes and PTCs. ${ }^{19,20,23}$ To investigate if the propensity of cells to undergo podocyte differentiation varied between different
A

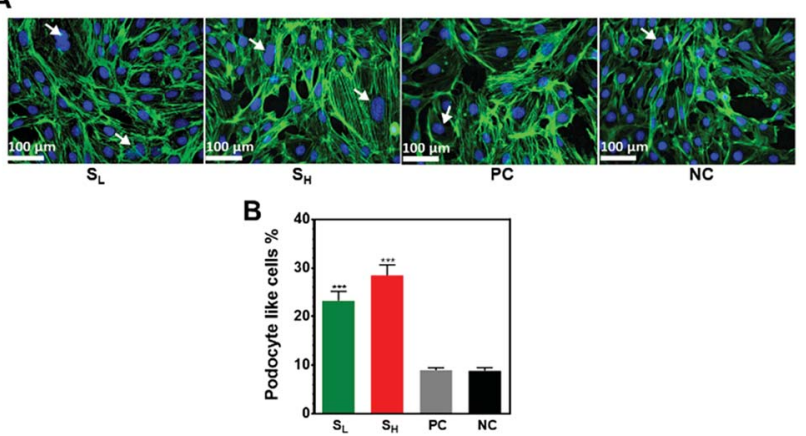

Fig. 3 (A) Fluorescent microscope images of mKSCs grown on silver nanoparticles modified $\left(\mathrm{S}_{\mathrm{L}}\right.$ and $\left.\mathrm{S}_{\mathrm{H}}\right)$ and control ( $\mathrm{PC}$ and $\mathrm{NC}$ ) surfaces for $96 \mathrm{~h}$. mKSCs were stained with phalloidin and DAPI to visualize the actin cytoskeleton and nuclei, respectively. Arrowheads indicate podocyte like cells. (B) Quantification of podocytes like-cells on the surfaces after $96 \mathrm{~h}$ of cell seeding was performed by identifying and counting the cells in the images. Results represent as the mean \pm SEM from 3 biological and technical replicates. $* * * p<0.001$. Asterisks indicate statistical significance compared to the uncoated glass coverslips (NC).

substrates, we first measured the extent of cell spreading, because podocyte-like cells tend to have a large cytoplasm : nuclear ratio. F-Actin staining was used to facilitate evaluation of cell spreading area (Fig. 3A). The average spreading areas of cells seeded on silver nanoparticle modified surfaces was nearly twice larger compared to glass coverslip control with (PC) or without (NC) a methyl oxazoline plasma polymer coating. The significant increase of cell spreading area on samples containing nanoparticles strongly suggests that the silver nanoparticles play a role in driving the observed phenomenon.

In some cells, F-actin staining showed a pattern typical of that in primary podocytes. These cells tended to be highly arborized and were often binucleate, all of which are typical characteristics of podocytes. The percentage of podocyte like cells on silver treated samples particularly on the $S_{H}$ samples was significantly higher than the controls (Fig. 3B). Upon differentiation, on both samples containing AgNPs@MSA, mKSCs increased in cell size, developed binucleate cells with arborized morphology (Fig. 3A) after 96 h. Immunostaining analysis showed the expression of podocyte specific marker podocalyxin by mKSCs cultured on the silver containing substrates. Representative images are provided in the ESI (Fig. SI $2 \dagger$ ). The data also suggests that the greater silver concentration facilitate differentiation of mKSCs into podocytelike cells.

Actin cytoskeleton have key roles in physiological function of podocytes and maintenance of glomerular filtration barrier. ${ }^{33-35}$ Several studies have reported that mutation or changes in the actin cytoskeleton lead to dysfunctional podocytes and subsequent proteinuria. ${ }^{33,36-38}$ No disruption in the actin cytoskeleton organization was observed on the silver treated substrates (Fig. 3A). Our results therefore confirm that the silver did not induce any derangement of the actin cytoskeleton. 


\section{Proximal tubule cell differentiation}

To examine the differentiation of mKSCs to PTCs we have carried out staining for megalin. The data showed a greater number of megalin expressing cells on silver nanoparticles modified surfaces and particularly on those with lower silver concentration $\left(\mathrm{S}_{\mathrm{L}}\right)$. The plasma polymer only coating did not show any notable difference to that of glass coverslip control (Fig. 4A), and these cells are significantly greater in number on the $\mathrm{S}_{\mathrm{L}}$ surfaces (Fig. $4 \mathrm{~B}$ ).

To further confirm the differentiation to PTCs we carried out staining for alkaline phosphatase, an enzyme that is expressed by PTCs. ${ }^{39}$ The images presented in Fig. 4C show significantly stronger alkaline phosphatase activity of mKSCs grown on $S_{L}$. This is in good agreement with the data obtained from the megalin assays and further strengthen the finding that silver may be stimulating mKSCs to differentiate into PTCs.

The silver nanoparticle modified surfaces appeared to trigger differentiation of mKSCs to podocyte and PTCs lineage. There are at least two possible explanations for the observed phenomena. Silver nanoparticles have been shown to cause oxidative stress in MSCs and in this way drive the differentiation of these cells. ${ }^{12}$ It may be possible that this is the reason behind the current findings pointing to increased differentiation of the mKSCs when silver was present. On another hand, the silver nanoparticles create surface roughness (Fig. S1†). We have demonstrated recently that tailored surface roughness, including roughness comparable with this inherent for the
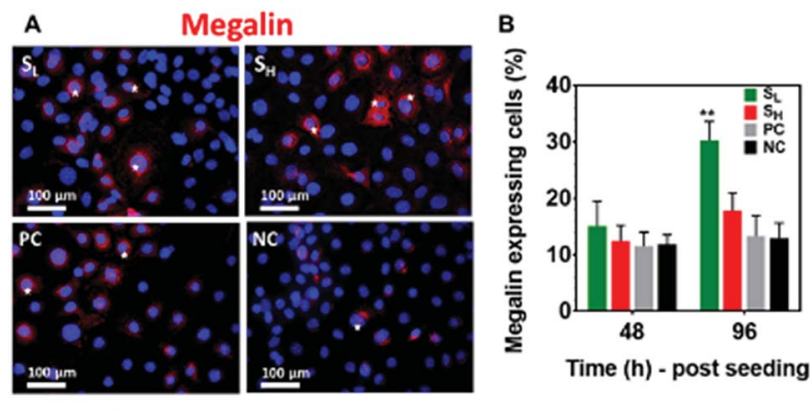

C

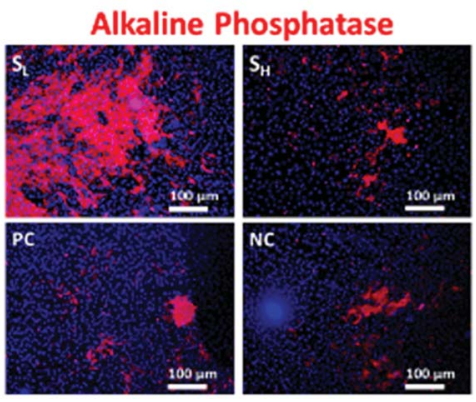

Fig. 4 (A) Immunostaining shows megalin ${ }^{+}$(red) expressing mKSCs. Nuclei were stained with DAPI (blue). Asterisks indicate cells expressing megalin. (B) Quantification of megalin expressing cells on the surfaces after 48 and $96 \mathrm{~h}$ of cell seeding was performed by identifying and counting the cells in the images. Data expressed as \pm SEM. $* * p<0.01$. Asterisks indicate statistical significance compared to the uncoated glass coverslips (NC). (C) Alkaline phosphatase (ALP, red) activity expression by mKSCs cultured on the silver rich $\left(S_{L}, S_{H}\right)$, plasma modified and unmodified glass substrates. model samples used in this study, was capable of guiding the differentiation of mKSCs to podocytes. ${ }^{23}$ This finding was not surprising since it is now well accepted that surface nanotopography has significant influence on the fate of various types of cells, including immune and stem cells..$^{27,40,41}$

\section{Conclusions}

Novel clinical approaches that involve the use of nanoengineered biomaterials to support and/or direct the differentiation and/or renewal of podocytes and PTCs, are urgently required to combat ESRD. Furthermore, the increasing use of silver in biomedical and consumer products require better understanding of the effect of this element on the fate of kidney stem cells. The results of this study showed that the AgNPs@MSA containing substrates $\left(\mathrm{S}_{\mathrm{L}}\right.$ and $\left.\mathrm{S}_{\mathrm{H}}\right)$ affect the viability, spreading, proliferation, population doubling time and differentiation of mKSCs to podocytes and PTCs as evaluated from the expression of markers. Bioreactors, cell culture substrates, cell therapies and tissue engineering constructs may be able to benefit from the antibacterial effect of silver nanoparticles and their capacity to stimulate mKSCs differentiation. However, before the later becomes a real opportunity much further work is required to fully and mechanistically understand how and in what direction silver nanoparticles affect the fate of kidney cells. Whether, the observed increased cell differentiation is due to surface nanoroughness or due to generation of reactive oxygen species, the combined effect of both, or due to other factors coming into play will be the subject of future studies.

\section{Conflicts of interest}

There are no conflicts to declare.

\section{Acknowledgements}

N. R. C gratefully acknowledges the Australian Government Research Training Program Scholarship from the Australian Federal Government and UniSA for International Travel Award. K. V. thanks ARC for DP15104212, NHMRC for Fellowship APP1122825 and Project grant APP1032738, and the Alexander von Humboldt Foundation for Fellowship for Experienced Researchers.

\section{References}

1 K. Chaloupka, Y. Malam and A. M. Seifalian, Trends Biotechnol., 2010, 28, 580-588.

2 X. Chen and H. J. Schluesener, Toxicol. Lett., 2008, 176, 1-12.

3 S. Chernousova and M. Epple, Angew. Chem., Int. Ed., 2013, 52, 1636-1653.

4 B. Schäfer, J. Tentschert and A. Luch, Environ. Sci. Technol., 2011, 45, 7589-7590.

5 B. Schäfer, J. Vom Brocke, A. Epp, M. Götz, F. Herzberg, C. Kneuer, Y. Sommer, J. Tentschert, M. Noll and I. Günther, Arch. Toxicol., 2013, 87, 2249-2262. 
6 S. Taheri, A. Cavallaro, S. N. Christo, L. E. Smith, P. Majewski, M. Barton, J. D. Hayball and K. Vasilev, Biomaterials, 2014, 35, 4601-4609.

7 S. Taheri, K. Vasilev and P. Majewski, Recent Pat. Mater. Sci., 2015, 8, 166-175.

8 J. W. Alexander, Surg. Infect., 2009, 10, 289-292.

9 P. V. AshaRani, G. Low Kah Mun, M. P. Hande and S. Valiyaveettil, ACS Nano, 2009, 3, 279-290.

10 R. Foldbjerg, D. A. Dang and H. Autrup, Arch. Toxicol., 2011, 85, 743-750.

11 C. Greulich, D. Braun, A. Peetsch, J. Diendorf, B. Siebers, M. Epple and M. Koller, RSC Adv., 2012, 2, 6981-6987.

12 W. He, T. A. Elkhooly, X. Liu, A. Cavallaro, S. Taheri, K. Vasilev and Q. Feng, J. Mater. Chem. B, 2016, 4, 1466-1479.

13 C. Zoccali, A. Kramer and K. J. Jager, NDT Plus, 2009, 3, 213224.

14 P. Murray, K. Vasilev, C. F. Mora, E. Ranghini, H. Tensaout, A. Rak-Raszewska, B. Wilm, D. Edgar, R. D. Short and S. E. Kenny, Biochem. Soc. Trans., 2010, 38, 1062-1066.

15 M. H. Little, Cell Death Dis., 2016, 2, 16053.

16 M. H. Little and A. P. McMahon, Cold Spring Harbor Perspect. Biol., 2012, 4, a008300.

17 N. Nakhoul and V. Batuman, in Experimental Models for Renal Diseases, Karger Publishers2011, vol. 169, pp. 37-50.

18 H. Pavenstädt, W. Kriz and M. Kretzler, Physiol. Rev., 2003, 83, 253-307.

19 C. Fuente Mora, E. Ranghini, S. Bruno, B. Bussolati, G. Camussi, B. Wilm, D. Edgar, S. E. Kenny and P. Murray, Stem Cells Dev., 2011, 21, 296-307.

20 E. Ranghini, C. F. Mora, D. Edgar, S. E. Kenny, P. Murray and B. Wilm, PLoS One, 2013, 8, e62953.

21 W. Chen, L. G. Villa-Diaz, Y. Sun, S. Weng, J. K. Kim, R. H. W. Lam, L. Han, R. Fan, P. H. Krebsbach and J. Fu, ACS Nano, 2012, 6, 4094-4103.

22 L. C. Y. Lee, N. Gadegaard, M. C. de Andrés, L.-A. Turner, K. V. Burgess, S. J. Yarwood, J. Wells, M. SalmeronSanchez, D. Meek, R. O. C. Oreffo and M. J. Dalby, Biomaterials, 2017, 116, 10-20.

23 M. MacGregor-Ramiasa, I. Hopp, A. Bachhuka, P. Murray and K. Vasilev, Acta Biomater., 2017, 56, 171-180.

24 K. Vasilev, A. Michelmore, P. Martinek, J. Chan, V. Sah, H. J. Griesser and R. D. Short, Plasma Processes Polym., 2010, 7, 824-835.
25 J. E. Sader, J. W. Chon and P. Mulvaney, Rev. Sci. Instrum., 1999, 70, 3967-3969.

26 S. Shankland, J. Pippin, J. Reiser and P. Mundel, Kidney Int., 2007, 72, 26-36.

27 R. V. Goreham, A. Mierczynska, L. E. Smith, R. Sedev and K. Vasilev, RSC Adv., 2013, 3, 10309-10317.

28 J. C. Ruiz, S. Taheri, A. Michelmore, D. E. Robinson, R. D. Short, K. Vasilev and R. Förch, Plasma Processes Polym., 2014, 11, 888-896.

29 J. Hernandez-Lopez, R. Bauer, W.-S. Chang, G. Glasser, D. Grebel-Koehler, M. Klapper, M. Kreiter, J. Leclaire, J.-P. Majoral and S. Mittler, Mater. Sci. Eng., C, 2003, 23, 267-274.

30 M. Ramiasa, A. Cavallaro, A. Mierczynska, S. Christo, J. Gleadle, J. Hayball and K. Vasilev, Chem. Commun., 2015, 51, 4279-4282.

31 D. L. Schmidt, C. E. Coburn, B. M. DeKoven, G. E. Potter, G. F. Meyers and D. A. Fischer, Nature, 1994, 368, 39-41.

32 G. Tillet, B. Boutevin and B. Ameduri, Prog. Polym. Sci., 2011, 36, 191-217.

33 C. Faul, M. Donnelly, S. Merscher-Gomez, Y. H. Chang, S. Franz, J. Delfgaauw, J.-M. Chang, H. Y. Choi, K. N. Campbell and K. Kim, Nat. Med., 2008, 14, 931-938.

34 P. Mundel and J. Reiser, Kidney Int., 2010, 77, 571-580.

35 J. Reiser, V. Gupta and A. D. Kistler, Kidney Int., 2010, 77, 662-668.

36 L. Perico, S. Conti, A. Benigni and G. Remuzzi, Nat. Rev. Nephrol., 2016, 12, 692-710.

37 X. Tian and S. Ishibe, Nephrol. Dial. Transplant., 2016, 31, 1577-1583.

38 C. Wei, C. C. Möller, M. M. Altintas, J. Li, K. Schwarz, S. Zacchigna, L. Xie, A. Henger, H. Schmid and M. P. Rastaldi, Nat. Med., 2007, 14, nm1696.

39 E. D. Wachsmuth and J. P. Stoye, Histochemistry, 1976, 47, 315-337.

40 Z. Chen, A. Bachhuka, S. Han, F. Wei, S. Lu, R. M. Visalakshan, K. Vasilev and Y. Xiao, ACS Nano, 2017, 11, 4494-4506.

41 S. N. Christo, A. Bachhuka, K. R. Diener, A. Mierczynska, J. D. Hayball and K. Vasilev, Adv. Healthcare Mater., 2016, 5, 956-965. 